\title{
Reaching the Depths through Three-Dimensional Irrigation - A Review
}

\author{
Vipul Gupta ${ }^{1}$, Mandeep S. Grewal $^{2}$, Ashtha Arya ${ }^{3}$, Anshul Arora ${ }^{4}$, Aditi Goel ${ }^{5}$ \\ 1, 2,3, 4, 5 Department of Conservative Dentistry and Endodontics, \\ SGT University, Budhera, Gurugram, Haryana, India.
}

\section{ABSTRACT}

The main goal of an endodontic therapy is thorough debridement of root canal system thus, "THREE DIMENSIONAL" cleaning is an essential factor in an endodontic procedure. The irrigant facilitates the removal of biofilm / microorganisms, tissue remnants and dentine chips from the root canal. It also acts as a lubricating agent and helps in the root canal instrumentation by reducing the excess friction that is generated. Only the three dimensional cleaning of the canals can guarantee the three dimensional sealing along with the long term success of endodontic treatment. Large areas of the main canal remain untouched after instrumentation thus, emphasising the importance of chemical cleaning and disinfection. The classic irrigant delivering approach is ineffective particularly in the apical third, isthmus, curves and fins. As there is no ideal root canal irrigant that serves all the objectives, they are used in combinations or in a specific sequence. Currently, there exists difference in opinions regarding the potential to three-dimensional cleaning of the canal system leading to the introduction of several mechanical devices for improving the penetration and safety of the entire process. These devices can be divided into 2 broad categories, manual agitation techniques and machine-assisted agitation devices. The manual irrigation system using needles is still widely accepted by general practitioners and endodontists while the newer machine assisted devices are making their way in leaps and bounds. This review focuses on the hydrodynamic disinfection of canals and provides us with the cutting-edge information on the most recent developments while making it evident that integration of newer technologies, coupled with enhanced techniques and materials may help in elevating our everyday clinical practice. Also brief description of various endodontic irrigation devices and their mechanism governing their efficacy is given.

\section{KEY WORDS}

Root Canal Irrigation, Vapour Lock, Irrigation Devices, IrriFlex, EndoVac, EndoActivator, Photo-Activated Disinfection
Corresponding Author: Dr. Ashtha Arya, Department of Conservative Dentistry and Endodontics, Faculty of Dental Sciences, SGT University, Budhera, Gurugram, Haryana, India. E-mail: drashthaarya@yahoo.co.in

DOI: $10.14260 /$ jemds/2021/84

How to Cite This Article: Gupta V, Grewal MS, Arya A, et al. Reaching the depths through three-dimensional irrigation - a review. J Evolution Med Dent Sci 2021;10(06):381-386, DOI: 10.14260/jemds/2021/84

Submission 02-10-2020,

Peer Review 12-12-2020,

Acceptance 18-12-2020,

Published 08-02-2021.

Copyright (C) 2021 Vipul Gupta et al. This is an open access article distributed under Creative Commons Attribution License [Attribution 4.0 International (CC BY 4.0)] 


\section{BACKGROUND}

Root canal system contains branches that communicate with the attachment apparatus frucally, laterally, and often terminate apically into multiple exits. Thus, for successful endodontic treatment there should be perfect eradication of microbes from the root canal. The biological objective of irrigation is to eliminate the root canal environment as a source of irritation to the apical region while the mechanical objective is to promote the 3-dimensional cleaning and obturation of the complex root anatomy. ${ }^{1}$

Efficient irrigation depends on the irrigating solution and the irrigant delivery system. Some of the popular irrigants include sodium hypochlorite, chlorhexidine, ethylenediaminetetraacetic acid (EDTA), citric acid, MTAD and alcohol. ${ }^{2}$ Haapasalo stated that an ideal root canal irrigant should have good washing action, perform lubrication, dissolve organic / inorganic debris, a broad spectrum of action, deeper depth of penetration, and most importantly it should be biocompatible with the surrounding tissues. At present, no irrigating solution has all the above properties and cannot be regarded as optimal. Hence, they all are used in combination with each other in a correct sequence for it to yield maximum cleaning efficacy. ${ }^{3}$

Various efforts have been made to develop systems that are safer and convenient to introduce and agitate the irrigating solution into the root anatomies. All the currently available devices are grouped into manual (conventional irrigation technique using different syringes and cannulas) and machineassisted agitation devices (rotary brushes, sonic, ultrasonic, pressure alteration devices etc.) that appear to improve the cleaning ability as compared to the conventional technique. Newer advancements (lasers, ozone, nanoparticles etc.) are also looked into for better results leading to cleaner canals. ${ }^{4,5}$

This article reviews the biological and chemical aspects along with the products and procedures for hydro-dynamic disinfection of the tooth canals and also provides us with information on recent developments in the field of root canal irrigation.

\section{CHALLENGES IN ROOT CANAL IRRIGATION}

\section{Smear Layer}

Smear layer is formed in the areas that have been instrumented inside the canal and contains both organic and inorganic debris. Many controversies exist regarding its removal or retention. Williams \& Goldman showed that smear layer slowed down the movement of Proteus vulgaris with time but bacterial penetration still occurred. ${ }^{6}$ Kennedy et al. showed that smear layer removal resulted in better sealing of obturation. While in necrotic cases its removal resulted in reaching the depths of dentinal tubules for deeper and better cleaning. ${ }^{7}$

\section{Biofilm}

Biofilm is a niche of microbes inside the canal system. Any remaining organic matter, vital / necrotic tissue and microbes sacrifice the integrity of obturation. Thus, it is the ultimate goal to completely remove them.

\section{Reaching the Depths}

Accessory canals, fins and isthmus are few complexities of the root canals and they are frequently packed with the debris during instrumentation. Cleaning and removal of debris, pulp tissue and biofilm from such difficult to reach areas which remain away from the reach of instrument relies completely on the chemical means and therefore it acts as a greater challenge. ${ }^{8}$

\section{Safety vs Efficacy}

The main challenge during cleaning and shaping is to maintain a proper balance in its efficacy and its safety to the periapical tissues. Effective and complete removal of the microbes in the apical region while maintaining a minimal apical pressure should be the ultimate goal. ${ }^{3}$

\section{Vapour Lock}

Concern over the block in the irrigant penetration in the apical part of the root canal due to the presence of gas bubbles has been expressed recently. Studies done by Vera et al. termed this as apical vapour lock. Peeters \& Gutknecht 2013, attributed it to the entrapment of air bubbles by the advancing irrigant front during delivery in a dry canal or the fusion of gas bubbles produced by the reaction between sodium hypochlorite $(\mathrm{NaOCl})$ and necrotic pulp. ${ }^{9}$ It has been argued that these bubbles cannot be removed by conventional syringe irrigation and activation techniques are necessary to overcome this limitation (Schoeffel 2008, Gu et al. 2009). ${ }^{10}$

\section{IRRIGATING SOLUTIONS}

\section{Sodium Hypochlorite}

Still considered a gold standard for endodontic irrigation due to its cost-effectiveness, excellent anti-bacterial effect, dissolution of necrotic tissue and biofilm and longer shelf life. When used in ranges from $0.5 \%-6 \%$, its mode of action is the formation of hypochlorous acid and subsequent release of chlorine ion. Radcliffe et al. observed that Enterococcus faecalis reduced its CFU / $\mathrm{mL}$ to zero when exposed to $0.5 \%$ $\mathrm{NaOCl}$ for 30 minutes, $1 \% \mathrm{NaOCl}$ for 10 minutes, $2.5 \% \mathrm{NaOCl}$ for 5 minutes and $5.25 \% \mathrm{NaOCl}$ for 2 minutes. ${ }^{11}$ Irrigation potential can be maximised by heating it, flooding the canals with large volumes, giving ample working time and refreshing it regularly. Unpleasant taste, toxicity and inability to remove the smear layer by itself are few of its limitations. ${ }^{12,13}$ In vitro studies have shown long term exposure of high concentration of $\mathrm{NaOCl}$ to have detrimental effects on dentine elasticity and its flexural strength. ${ }^{14}$

\section{EDTA}

A chelating agent used in concentrations of $17 \%$ or $15 \%$ to negotiate smaller canals and remove the inorganic part of the smear layer and acts as a lubricant and emulsifying agent. ${ }^{15}$ It holds the debris in a suspension when negotiating canals. It has little or no anti-microbial activity but works synergistically with other chemicals as it weakens the cell membrane.16,17 


\section{Citric Acid}

Citric acid has been a substitute to EDTA for a final rinse to remove the smear layer. It has a long history in root canal irrigation with $1 \%$ to $10 \%$ concentration used frequently. It is somewhat more aggressive than EDTA, and has a more pronounced erosion of dentine as seen with EDTA. ${ }^{18}$

\section{Chlorhexidine Digluconate}

Chlorhexidine is used in root canal treatment as a final wash after EDTA due to its good antimicrobial activity as it affects the cell wall and outer membrane. Since it does not dissolve the organic and inorganic matter, it cannot be used alone inside the canal. It comes with an added advantage of no bad smell / taste and less irritation to the periapical tissues as seen with $\mathrm{NaOCl}$. It kills the bacteria but is unable to remove the biofilm. ${ }^{19}$ Khademi AA stated its substantivity due to its binding to the hard tissue. Ferraz et al. showed that $2 \%$ chlorhexidine (CHX) gel has good antimicrobial activity when compared with other irrigants, including $\mathrm{NaOCl}^{20}$

\section{Solution Interactions while Irrigating}

- $\quad \mathrm{EDTA}+\mathrm{NaOCl}$ - when mixed, it results in a reduced amount of chlorine ions (Cl-ions) resulting in decreased activity of sodium hypochlorite.

- $\mathrm{NaOCl}+\mathrm{CHX}-$ Results in the formation of an orangishbrown precipitate called parachloroanaline, which is carcinogenic in nature.

- $\quad$ CHX + EDTA - white precipitate is formed which reduces its action.

\section{IRRIGATION DEVICES}

Along with the means of delivery, the involvement of some sort of agitation and the mode of agitation plays an important role in maximizing the cleaning efficacy. All the endodontic irrigation devices that are currently in use can be divided into manual and machine-assisted.

\section{Manual Techniques}

\section{Syringe Irrigation with Needle}

Widely used by the endodontists and general dentists, syringes and needles of various designs and sizes are incorporated either passively or actively. Use of leur lock syringes provide maximum safety and control as stated by Pasricha SK et al. ${ }^{3}$ Needle design and its tip play a crucial role on the flow pattern, flow velocity, depth of penetration and the pressure on the canal walls. Commercially available needles are open-ended (flat / bevelled / notched) and close-ended (side vented / double side vented / multiple vents). Boutsioukis et al. stated that the jet formed by the flat and bevelled needle is more intense and extends further apically than a closed needle. Also, studies have shown that a 21 gauge tip can reach the apex of an ISO size 80 canal similarly 23 gauge - 50 size canal, 25 gauge - 35 size canal and 30 gauge - can reach 25 size canal. 27 - and 30-gauge side vented needles are the most frequently used ones in endodontics. ${ }^{21,22}$ IrriFlex is a unique irrigation needle made of plastic with a back-to-back 2side vent design delivering solutions as close as possible to the apex. It has a soft polypropylene body, hence, IrriFlex offers ideal flexibility and reachability for improved irrigation therapies.

\section{Canal Brushes - NaviTip and NaviTip FX}

Ultradent introduced a 30-gauge irrigation needle covered by a brush known as NaviTip FX while a brushless one called the NaviTip was also launched. The brush helped by assisting in debridement of the canals. ${ }^{23}$ Al-Hadlaq showed improved results in the coronal third with NaviTip FX.24 While the drawback was the separation of radiolucent bristles into the canal irregularities which became difficult to be identified or removed as stated by Gu et al. ${ }^{4}$

\section{Manual Dynamic Irrigation}

The vapour lock effect makes it difficult for the irrigant to reach the apical portion. An efficient hydrodynamic effect is created when a well-fitted gutta-percha point is used in short up and down motion within the canal. Chattterjee et al. showed it to be better in removing intra radicular E. faecalis biofilm compared to conventional syringe irrigation. Similar results were given by Oliveri JG et al. it is simple and cost-effective, yet time consuming and laborious. ${ }^{25,26}$

\section{Machine Assisted Techniques \\ Rotary Brushes}

These are micro-brushes attached to a rotary handpiece. The Ruddle brush operates at 300rpm and has a tapered brush section attached to a shaft with bristles coming out of it radially. It is discontinued commercially in 2001 as it caused bristle separation. ${ }^{27}$ Also, available is a highly flexible microbrush moulded in polypropylene called the canal brush. Weise et al. showed them to remove debris effectively. Its use is restricted as Protogerou et al. stated that it did not produce cleaner canals. ${ }^{28}$

\section{Continuous Irrigation Devices}

- QUANTEC E (SybronEndo, Orange, CA) - SybronEndo came up with a self-contained fluid delivery unit continuous along with instrumentation. Set up comprises of a console pump, 2 irrigation reservoirs and tubing. It proposed to improve the debridement by increasing the volume of irrigation which in turn increases the irrigant contact time further facilitating a greater depth of penetration. Contrastingly, results by Setlock and Walters showed no significant difference between Quantec-E and conventional irrigation. ${ }^{29,30}$

- VATEA (ReDent Nova) - Self-contained fluid delivery device which is an integral part of self-adjusting file system. Its $400 \mathrm{~mL}$ reservoir pumps in the irrigant during instrumentation. The flow of irrigant can be controlled from 1 - $10 \mathrm{~mL} / \mathrm{min}$ using a foot pedal. Studies by Hof et al. concluded that SAF created no piston action and no apical extrusion while the time taken for the full exchange of irrigant at apical third was 30 seconds. Siqueira proved self-adjusting files (SAF) to be superior to nickel titanium (NITI) rotary instruments in oval canals ${ }^{23,31}$ 


\section{Sonic Irrigation Devices}

- Vibringe (Vibringe BV, Amsterdam, The Netherlands) - A single step system that combines syringe delivery with sonic activation. Developed by Vibringe BV as a cordless device which attaches to itself a $10 \mathrm{~mL}$ leur lock disposable syringe with any type of needle. It is a syringe and battery system that gives $9000 \mathrm{rpm}$. Rodig et al. stated it to be better than conventional syringe irrigation in apical third in removing debris. ${ }^{32}$

- EndoActivator (Advanced Endodontics, Santa Barbara, CA, USA) - A cordless, battery-operated device having a contra-angled design using sonics for endodontic irrigation. 3 colour coded polymer tips yellow, red and blue corresponding to sizes 15 / 02, 25 / 04 and 35 / 04 respectively can be attached to the handpiece. They vibrate at 10,000 rpm while moving the tip up and down in short strokes to safely and vigorously energize the hydrodynamic phenomenon. EndoActivator utilizes cavitation and acoustic streaming which significantly improves the debridement and disruption of the smear layer and biofilm. Caron $\mathrm{G}$ et al. reported effective cleaning of debris from lateral canals, smear layer removal and elimination of biofilm in the curved canals. 33

\section{Ultrasonics}

Ultrasonic irrigation can be of two types, one where instrumentation and ultrasonic irrigation is done simultaneously or passive ultrasonic irrigation where instrumentation is succeeded by ultrasonic irrigation. Ultrasonics delivers 25,000 vibrations per minute. Ultrasonics have shown to produce acoustic streaming and cavitation which play a role in maximising the biochemical activity of the irrigant. Gutart K, Burleson A stated that 1 minute of Ultrasonic agitation produces cleaner canals and isthmus in both vital and necrotic teeth. ${ }^{34,35}$

\section{Pressure Alternating Devices}

- RinsEndo - Durr Dental Co. developed a pressure-suction system for cleaning. It has a handpiece, a special cannula with $7 \mathrm{~mm}$ exit aperture and a syringe. $65 \mathrm{~mL}$ of rinsing solution with an oscillation frequency of $1.6 \mathrm{~Hz}$ can be delivered into the canal. It is said to suck back the used solution and air to mix it again with the irrigant to be delivered at a rate of 100 cycles / min. due to its pulsating nature, it can rinse the apical third while the needle is placed in the coronal portion. Contrary to claims, Mcgill found it to be less effective in removing stained collagen from the canals. ${ }^{36}$

- EndoVac (Discus Dental, Culver city, CA, USA) - This device uses apical negative pressure to increase irrigation safety. The setup comprises of a master delivery tip, macro cannula, micro cannula and a multiport adapter. It uses a newer approach wherein the irrigant is not delivered through a needle but introduced continuously into the pulp chamber using the master delivery tip. The macro and micro cannulas (placed apically inside the canals) use the negative pressure to pull this irrigant down the canal and back up again through the pores present on them. All this happens simultaneously forming a constant flow of fresh solution in the canal and exit of used solution out of it. Desai $P$ gave evidence for it to be considerably safer near the apical foramen ${ }^{41}$. Nielsen and Baumgartner showed lesser debris at apical $1 \mathrm{~mm}$ when using EndoVac. ${ }^{37}$ better microbial control was achieved in the studies by Hockett, Miller and Baumgartner. ${ }^{38}$

\section{RECENT ADVANCEMENTS IN ROOT CANAL IRRIGATION}

\section{Laser Pips}

A system that uses lasers in the root canal irrigation. The absorption of the laser by sodium hypochlorite leads to its vaporisation and formation of vapour bubbles, these expand and implode causing secondary cavitational effects. The lasers used can be a diode laser, Er: YAG, Nd: YAG which due to their high peak power along with short pulse duration show their photochemical effects. The PIPS tip is $9 \mathrm{~mm}$ long with 600 micron diameter and the tip is stripped off by $3 \mathrm{~mm}$ at its head for lateral emission of waves. The PIPS tip is kept at the canal orifice. Devito et al. stated PIPS to be better when compared with conventional procedures. ${ }^{39}$ Llyod also showed PIPS to remove organic debris at a greater level but complete elimination of the biofilm was not seen, Noiri et al. ${ }^{40,41}$

\section{Photo Activated Disinfection}

A recent concept where a photosensitizer (non-toxic dye) is introduced into the tooth canal which gets acted upon by a low-intensity light to release reactive oxygen species. The dye attaches to the cell, which on exposure to a special light source releases nascent oxygen and cause damage to cell membrane. The dye is said to have a lesser affinity towards the human cells, Komerik et al. Photo activated disinfection (PAD) is effective not only against bacteria but also against fungi, viruses and other microbes. ${ }^{42}$ The dye (toluidine blue 0 ) is introduced in the canal and let to sit for 60 seconds while light irradiation is done for 30 seconds. Bunsor, Schlafer found it to be successful in eliminating bacteria. It should not be thought of as an alternative rather a supplement to irrigation. 43,44

\section{Endo Irrigator Plus (K Dent Dental System)}

Designed by Dr Mandar Pimprikar, it follows activated continuous warm irrigation and evacuation system (ACWIS). It uses a pressure-assisted system which creates positive and negative pressure inside the canal. Operated employing a pedal, it comes with an inbuilt heater for $\mathrm{NaOCl}$ (raising its temperature to 50 degrees) alongside an inbuilt suction. Continuous irrigation caused by it helps in penetration of warm $\mathrm{NaOCl}$ into the lateral and accessory canals while the strong vacuum system ensures that $\mathrm{NaOCl}$ doesn't harm the peri-apex. Gadaalay et al. stated endo irrigator plus to be superior in cleaning than other contemporaries. Shetty $\mathrm{v}$ showed endo irrigator plus to extrude lesser debris periapically. Thus, it is known to provide efficient disinfection and cleaning in a relatively safe environment. 45

\section{Ozone}

Ozonated water, ozonated olive oil and ozone gas can be applied to the canals. Its triatomic nature causes it to be unstable and leads to its easy dissociation into cytotoxic 
species of oxygen. Systems such as Neo Ozone water-S unit, HealOzone (kavo), OzoTop have been put into commercial use. It should be used at the end of cleaning the canal as it works well when there is little organic debris. Nagayoshi et al. stated that for it to be effective, it should be used in good concentrations and for a sufficient amount of time. Inconsistent results produced by it stresses on the need for further studies. ${ }^{23,46}$

\section{Nanoparticles}

These particles are synthesized from silver, copper oxide and zinc oxide while having good antibacterial properties. Their positive charge causes electrostatic interactions between the negatively charged cell wall which is responsible for their activity.

\section{Sound Waves}

GentleWave by Sonendo, is a non-instrumentation technique, thus there is little or no enlargement of the root canal. Broadspectrum of sound wave transmission inside the canal is used to effectively clean the pulp, debris and microorganisms. It makes the treatment less stressful and less invasive by the movement of energised fluid across the canal anatomy. 47

\section{CONCLUSIONS}

In today's time, when dentistry is moving ahead with leaps and bounds, provision of dental treatment has become easier. Cleaning and disinfection of a root canal has become more patient friendly and predictable now due to the cutting edge technologies and recent developments in the field of endodontics. Irrigation plays a key role in successful root canal treatment because it reduces friction between the instrument and dentine, removes the organic and inorganic debris, dissolves tissue, and furthermore, most importantly has antimicrobial / antibiofilm effect. Irrigation is the only way to impact those areas of the root canal wall which remain untouched by mechanical instrumentation.

In the years to come, development of systems which can provide 3D cleaning will take our profession ahead and help us reach our goal of root canal disinfection. Biomechanical cleaning should be given utmost priority and dentists all around the world should take it as a challenge to achieve root canal irrigation with full efficiency and safety.

Financial or other competing interests: None.

Disclosure forms provided by the authors are available with the full text of this article at jemds.com.

\section{REFERENCES}

[1] Schilder H. Cleaning and shaping the root canal. Dent Clin North Am 1974;18(2):269-96.

[2] Zehnder M. Root canal irrigants. J Endod 2006;32(5):38998.

[3] Pasricha SK, Makkar S, Gupta P. Pressure alteration techniques in endodontics- a review of literature. J Clin Diagn Res 2015;9(3):ZE01-6.
[4] Gu LS, Kim JR, Ling J, et al. Review of contemporary irrigant agitation techniques and devices. J Endod 2009;35(6):791-804.

[5] Dua D, Dua A, Uppin VM. A scanning electron microscopic evaluation of intracanal smear layer removal by two different final irrigation activation systems. Contemp Clin Dent 2014;5(1):37-41.

[6] Williams S, Goldman M. Penetrability of the smeared layer by a strain of proteus vulgaris. J Endod 1985;11(9):385-8.

[7] Kennedy WA, Walker WA III, Gough RW. Smear layer removal effects on apical leakage. J Endod 1986;12(1):217.

[8] Paque F, Laib A, Gautschi H, et al. Hard-tissue debris accumulation analysis by high-resolution computed tomography scans. J Endod 2009;35(7):1044-7.

[9] Peeters HH, Gutknecht N. Efficacy of laser-driven irrigation versus ultrasonic in removing an airlock from the apical third of a narrow root canal. Aust Endod J 2013;40(2):47-53.

[10] John SG. The EndoVac method of endodontic irrigation, part 2 -- efficacy. Denti Today 2008;27(1):82,84,86-7.

[11] Radcliffe CE, Potouridou L, Qureshi R, et al. Antimicrobial activity of varying concentrations of sodium hypochlorite on the endodontic microorganisms actinomyces israelii, A. naeslundii, Candida albicans and enterococcus faecalis. Int Endod J 2004;37(7):438-46.

[12] Sirtes G, Waltimo T, Schaetzle M, et al. The effects of temperature on sodium hypochlorite short-term stability, pulp dissolution capacity and antimicrobial efficacy. J Endod 2005;31(9):669-71.

[13] Berutti E, Marini R. A scanning electron microscopic evaluation of the debridement capability of sodium hypochlorite at different temperatures. J Endod 1996;22(9):467-70.

[14] Marending M, Luder HU, Brunner TJ, et al. Effect of sodium hypochlorite on human root dentine--mechanical, chemical and structural evaluation. Int Endod J 2007;40(10):786-93.

[15] Yoshida T, Shibata T, Shinohara T, et al. Clinical evaluation of the efficacy of EDTA solution as an endodontic irrigant. J Endod 1995;21(12):592-3.

[16] Hottel TL, el-Refai NY, Jones JJ. A comparison of the effects of three chelating agents on the root canals of extracted human teeth. J Endod 1999;25(11):716-7.

[17] Hülsmann M, Heckendorff M, Lennon A. Chelating agents in root canal treatment: mode of action and indications for their use. Int Endod J 2003;36(12):810-30.

[18] Qian W, Shen Y, Haapasalo M. Quantitative analysis of the effect of irrigant solution sequences on dentin erosion. J Endod 2011;37:1437-41.

[19] Mcdonnell G, Russell AD. Antiseptics and disinfectants: activity, action and resistance. Clin Microbiol Rev 1999;12(1):147-79.

[20] Ferraz CC, Gomes BP, Zaia AA, et al. In vitro assessment of the antimicrobial action and the mechanical ability of chlorhexidine gel as an endodontic irrigant. J Endod 2001;27(7):452-5.

[21] Boutsioukis C, Gogos C, Verhaagen B, et al. The effect of root canal taper on the irrigant flow: evaluation using an unsteady computational fluid dynamics model. Int Endod J 2010;43(10):909-16.

[22] Boutsioukis C, Gogos C, Verhaagen B, et al. The effect of apical preparation size on irrigant flow in root canals 
evaluated using an unsteady computational fluid dynamics model. Int Endod J 2010;43(10):874-81.

[23] Elumalai D, Kumar A, Tewari RK, et al. Newer endodontic irrigation devices: an update. Journal of Dental and Medical Sciences 2014;13(6):4-8.

[24] Al-Hadlaq SM, Al-Turaiki SA, Al-Sulami U, et al. Efficacy of new brush-covered irrigation needle in removing root canal debris: a scanning electron microscopic study. J Endod 2006;32(12):1181-4.

[25] Chatterjee R, Venugopal P, Jyothi KN, et al. Effect of sonic agitation, manual dynamic agitation on removal of enterococcus faecalis biofilm. Saudi Endod J 2015;5(2):125-8.

[26] Olivieri JG, Font MG, Stober E, et al. Effect of manual dynamic activation with citric acid solutions in smear layer removal: a scanning electron microscopic evaluation. J Dent Sci 2016;11(4):360-4.

[27] Ruddle CJ. Microbrush for endodontic use. Washington, DC: United States Patent 6,179, 617. 2001.

[28] Weise M, Roggendorf MJ, Ebert J, et al. Four methods for cleaning simulated lateral extensions of curved root canals: a SEM evaluation. Int Endod J 2007;40:991-92.

[29] Setlock J, Fayad MI, BeGole E, et al. Evaluation of canal cleanliness and smear layer removal after the use of the quantec-E irrigation system and syringe: a comparative scanning electron microscope study. Oral Surg Oral Med Oral Pathol Oral Radiol Endod 2003;96(5):614-7.

[30] Walters MJ, Baumgartner JC, Marshall JG. Efficacy of irrigation with rotary instrumentation. J Endod 2002;28(12):837-9.

[31] Hof R, Perevalov V, Eltanani M, et al. The self-adjusting file (SAF). Part 2: mechanical analysis. J Endod 2010;36(4):691-6.

[32] Rödig T, Bozkurt M, Konietschke F, et al. Comparison of the vibringe system with syringe and passive ultrasonic irrigation in removing debris from simulated root canal irregularities. J Endod 2010;36(8):1410-13.

[33] Caron G. Cleaning efficiency of the apical millimeters of curved canals using three different modalities of irrigant activation: an SEM study. Masters thesis, Paris VII University, Paris, France 2007.

[34] Gutarts R, Nusstein J, Reader A, et al. In vivo debridement efficacy of ultrasonic irrigation following hand-rotary instrumentation in human mandibular molars. J Endod 2005;31(3):166-70.

[35] Burleson A, Nusstein J, Reader A, et al. The in vivo evaluation of hand/rotary/ultrasound instrumentation in necrotic, human mandibular molars. J Endod 2007;33(7):782-7.
[36] McGill S, Gulabivala K, Mordan N, et al. The efficacy of dynamic irrigation using a commercially available system (RinsEndo) determined by removal of a collagen 'biomolecular film' from an ex vivo model. Int Endod J 2008;41(7):602-8.

[37] Nielsen BA, Craig Baumgartner J. Comparison of the EndoVac system to needle irrigation of root canals. J Endod 2007;33(5):611-15.

[38] Hockett JL, Dommisch JK, Johnson JD, et al. Antimi-crobial efficacy of two irrigation techniques in tapered and nontapered canal preparations: an in vitro study. J Endod 2008;34(11):1374-77.

[39] DiVito E, Peters OA, Olivi G. Effectiveness of the erbium: YAG laser and new design radial and stripped tips in removing the smear layer after root canal instrumentation. Lasers Med Sci 2012;27(2):273-80.

[40] Lloyd A, Uhles JP, Clement DJ, et al. Elimination of intracanal tissue and debris through a novel laseractivated system assessed using high-resolution microcomputed tomography: a pilot study. J Endod 2014;40(4):584-7.

[41] Noiri Y, Katsumoto T, Azakami H, et al. Effects of Er: YAG laser irradiation on biofilm-forming bacteria associated with endodontic pathogens in vitro. J Endod 2008;34(7):826-9.

[42] Kömerik N, Curnow A, MacRobert AJ, et al. Fluorescence biodistribution and photosensitising activity of toluidine blue on rat buccal mucosa. Lasers Med Sci 2002;17(2):8692.

[43] Bonsor SJ, Nichol R, Reid TMS, et al. Microbiological evaluation of photo-activated disinfection in endodontics (an in vivo stu dy). Br Dent J 2006;200:337-41.

[44] Schlafer S, Vaeth M, Horsted-Bindslev P, et al. Endodontic photoactivated disinfection using a conventional light source: an in vitro and ex vivo study. Oral Surg Oral Med Oral Pathol 2010;109(4):634-41.

[45] Gadaalay S, Hariramani SI, Dhore P, et al. Comparative evaluation of efficacy of three different irrigation activation systems in debridement of root canal isthmus: An in vitro study. Endodontology 2017;29(1):39-42.

[46] Nagayoshi M, Fukuizumi T, Kitamura C, et al. Efficacy of ozone on survival and permeability of oral microorganisms. Oral Microbiol Immunol 2004;19(4):240-6.

[47] Sigurdsson A, Garland RW, Le KT, et al. 12-month healing rates after endodontic therapy using the novel GentleWave system: a prospective multicenter clinical study. J Endod 2016;42(7):1040-8. 